\title{
Average Poisson's ratio for crystals. Hexagonal auxetics
}

\author{
R.V. Goldstein, V.A. Gorodtsov, D.S. Lisovenko ${ }^{\dagger}$ \\ A.Yu. Ishlinsky Institute for Problems in Mechanics RAS, prospect Vernadskogo 101-1, 119526 Moscow \\ †lisovenk@ipmnet.ru
}

\section{Средний коэффициент Пуассона для кристаллов. Гексаго- нальные ауксетики}

\author{
Гольдштейн Р. В., Городцов В. А., Лисовенко Д. С. \\ Институт проблем механики им. А.Ю. Ишлинского РАН, просп. Вернадского 101-1, 119526 Москва
}

In the paper hexagonal auxetics are analyzed. The necessary and sufficient conditions are obtained for the detection of hexagonal auxetics and auxetics on average over all transverse directions. Also, necessary and sufficient conditions are obtained for the triclinic crystals with average Poisson's ratio when averaged over transverse directions. Necessary conditions are given for some special orientations. Eleven crystals with average negative Poisson's ratio are revealed if the averaging is performed over all three orientation angles.

Keywords: Poisson's ratio, average Poisson's ratio, auxetics, hexagonal auxetics.

\section{Introduction}

Anisotropy of different crystals is reflected in the diversity of their properties depending on the orientation relative to the crystallographic axes. Under the parameterization of this orientation by three angular variables (Euler's angles), in the case of uniaxial tensile strain the dependence on the angle $\psi$ describing the rotation of the crystal in the transverse plane with respect to the direction of extension is the most simple. The general structure of the angular dependence of the relation of Poisson's ratio $v(\varphi, \theta, \psi)$ to Young's modulusE $(\varphi, \theta)$ has the form (see, in particular [1])

$$
\begin{gathered}
-\frac{v}{\mathrm{E}}=\mathrm{A}(\varphi, \theta) \cos ^{2} \psi+\mathrm{B}(\varphi, \theta) \cos ^{2} \psi+ \\
+\mathrm{D}(\varphi, \theta) \cos \psi \sin \psi \\
\mathrm{A}=\left.\frac{-v}{\mathrm{E}}\right|_{\psi=0}, \mathrm{~B}=\left.\frac{-v}{\mathrm{E}}\right|_{\psi=\pi / 2}, \mathrm{D}+\mathrm{A}+\mathrm{B}=\left.\frac{-v}{\mathrm{E}}\right|_{\psi=\pi / 4}
\end{gathered}
$$

By averaging over the transverse directions we obtain

$$
-\frac{\bar{v}}{\mathrm{E}} \equiv-\frac{1}{2 \pi} \int_{0}^{2 \pi} \mathrm{d} \psi \frac{v}{\mathrm{E}}=\frac{1}{2}[\mathrm{~A}(\varphi, \theta)+\mathrm{B}(\varphi, \theta)] .
$$

В статье проанализированы гексагональные ауксетики. Получены необходимые и достаточные условия для обнаружения гексагональных ауксетиков и ауксетиков в среднем при осреднении по поперечным направлениям. Также получены необходимые и достаточные условия для триклинных кристаллов со средним коэффициентом Пуассона при осреднении по поперечным направлениям. Для некоторых частных ориентаций записаны необходимые условия. Выявлены одиннадцать кристаллов, у которых коэффициент Пуассона является отрицательным при осреднении по всем трем углам.

Ключевые слова: коэффициент Пуассона, средний коэффициент Пуассона, ауксетики, гексагональные ауксетики.

If the average is taken over all three angles, we find

$$
\begin{gathered}
-<v>\equiv-\frac{1}{8 \pi^{2}} \int_{0}^{2 \pi} \mathrm{d} \psi \int_{0}^{2 \pi} \mathrm{d} \varphi \int_{0}^{\pi} \mathrm{d} \theta \sin \theta \nu(\varphi, \theta, \psi)= \\
=\frac{1}{2}(<\mathrm{AE}>+<\mathrm{BE}>)
\end{gathered}
$$

\section{Hexagonal auxetics}

Analysis of cubic crystals as the most symmetric [2-4] is the most simple. Hexagonal crystals are next in simplicity. Their elastic properties are independent of the angle $\varphi$, i.e. there is the transverse isotropy. In this case we have

$$
\begin{gathered}
\mathrm{A}=\mathrm{s}_{12} \sin ^{2} \theta+\mathrm{s}_{13} \cos ^{2} \theta, \\
\mathrm{B}=\mathrm{s}_{13} \cos ^{2} 2 \theta+\mathrm{Q} \sin ^{2} \theta \cos ^{2} \theta, \mathrm{D}=0 \\
\frac{1}{\mathrm{E}}=\left(\sqrt{\mathrm{s}_{11}} \sin ^{2} \theta-\sqrt{\mathrm{s}_{33}} \cos ^{2} \theta\right)^{2}+ \\
+\left(\mathrm{s}_{44}+2 \mathrm{~s}_{13}+2 \sqrt{\mathrm{s}_{11} \mathrm{~s}_{33}}\right) \sin ^{2} \theta \cos ^{2} \theta, \\
\mathrm{Q} \equiv \mathrm{s}_{11}+\mathrm{s}_{33}+2 \mathrm{~s}_{13}-\mathrm{s}_{44}, \quad \mathrm{E}>0
\end{gathered}
$$


Here positivity of Young's modulus is obvious by the thermodynamic restrictions on the compliance coefficients of hexagonal crystals

$$
\begin{gathered}
\mathrm{s}_{11}>0, \quad \mathrm{~s}_{33}>0, \quad \mathrm{~s}_{44}>0 \\
1>0.5\left(\mathrm{~s}_{11}+\mathrm{s}_{12}\right) / \mathrm{s}_{11}>\mathrm{s}_{13}^{2} /\left(\mathrm{s}_{11} \mathrm{~s}_{33}\right) .
\end{gathered}
$$

The formula for the relation of Poisson's ratio to Young's modulus for hexagonal crystals takes the form

$$
\begin{aligned}
& -\frac{v}{E}=\left(s_{12} \sin ^{2} \theta+s_{13} \cos ^{2} \theta\right) \cos ^{2} \psi+ \\
& +\left(s_{13} \cos ^{2} 2 \theta+\frac{1}{4} Q \sin ^{2} 2 \theta\right) \sin ^{2} \psi .
\end{aligned}
$$

Three necessary conditions for the complete hexagonal auxetics, i.e. hexagonal crystals with a negative Poisson's ratio for all orientations of the crystals, can be obtained in the case of three particular directions $\psi=\theta=0 ; \psi=0, \theta=\pi / 2$ and $\psi=2 \theta=\pi / 2$

$$
\mathrm{s}_{13}>0, \mathrm{~s}_{12}>0, \mathrm{Q}>0 \text {. }
$$

These conditions are also sufficient for complete auxetics. Under these conditions the right side of the formula (1) for the relation of Poisson's ratio to positive Young's modulus is positive. This result was obtained earlier in [5]. The opposite inequalities

$$
\mathrm{s}_{13}<0, \mathrm{~s}_{12}<0, \mathrm{Q}<0
$$

provide necessary and sufficient conditions for nonauxetics, crystals with a positive Poisson's ratio for all their orientations. If not all of these inequalities are satisfied, then we have the case of hexagonal partial auxetics, crystals with a negative Poisson's ratio in some orientations, and positive for others.

Analysis of experimental data on the hexagonal crystals, collected in reference [6], showed that only six crystals are Elastic parameters of partial hexagonal auxetics. partial auxetics, and complete auxetics are absent. Only two of the three inequalities (6) are satisfied for these partial auxetics, as clearly from Table 1.

Further, in accordance with (2), (4), (5) we have for Poisson's ratio, averaged over the transverse directions

$$
-2 \frac{\bar{v}}{\mathrm{E}}=-\left.2 \frac{\mathrm{v}}{\mathrm{E}}\right|_{\psi=\pi / 4}=\mathrm{s}_{12} \sin ^{2} \theta+\mathrm{s}_{13}\left(\cos ^{2} \theta+\cos ^{2} 2 \theta\right)
$$

Here, three particular orientations $\theta=0, \theta=\pi / 2, \theta=\pi / 4$ will correspond to the necessary conditions of the form

$$
\mathrm{s}_{13}<0, \quad \mathrm{~s}_{12}+\mathrm{s}_{13}<0, \quad 2 \mathrm{~s}_{12}+2 \mathrm{~s}_{13}+\mathrm{Q}<0
$$

that are performed for six partial auxetics (see Table 1). As can be seen from (7), the same conditions (6) remain to be among the sufficient conditions for the nonauxetics on average. They are not satisfied for these crystals. However, after rearrangement of the terms in the expression (7) it takes the form

$$
-2 \frac{\bar{v}}{E}=s_{13}\left(\cos ^{2} \theta+\cos ^{2} 2 \theta\right)+\left(s_{13}+Q \cos ^{2} \theta\right) \sin ^{2} \theta
$$

This expression corresponds to sufficient conditions for the nonauxetics on average

$$
\mathrm{s}_{13}<0, \mathrm{~s}_{12}<0, \mathrm{~s}_{12}+\mathrm{Q}<0
$$

which are satisfied for the three partial auxetics $\mathrm{Be}, \mathrm{C}_{7} \mathrm{H}_{12}$, $\mathrm{TiB}_{2}$ (see Table 1 ). Other conditions

$$
\mathrm{s}_{13}+\mathrm{s}_{12}<0, \mathrm{~s}_{13}-\mathrm{s}_{12}<0, \mathrm{Q}<0
$$

are sufficient for the negativity of the right-hand side of (7), as clearly after the transformations to the form

Table 1.

\begin{tabular}{|c|c|c|c|c|c|c|c|c|c|c|}
\hline $\begin{array}{c}\text { Hexagonal } \\
\text { crystal }\end{array}$ & $\mathrm{s}_{12}$, \\
$\mathrm{TPa}^{-1}$ & $\mathrm{~s}_{13}$, & $\begin{array}{c}\mathrm{Q}, \\
\mathrm{TPa}^{-1}\end{array}$ & $\begin{array}{c}\mathrm{s}_{12}+\mathrm{s}_{13}, \\
\mathrm{TPa}^{-1}\end{array}$ & $\begin{array}{c}\mathrm{s}_{13}-\mathrm{s}_{12}, \\
\mathrm{TPa}^{-1}\end{array}$ & $\begin{array}{c}2 \mathrm{~s}_{12}+2 \mathrm{~s}_{13}+\mathrm{Q}, \\
\mathrm{TPa}^{-1}\end{array}$ & $\begin{array}{c}\mathrm{s}_{12}+\mathrm{Q}, \\
\mathrm{TPa}^{-1}\end{array}$ & $\bar{v}_{\text {min }}$ & $\bar{v}_{\text {max }}$ & $<\mathrm{v}>$ \\
\hline $\mathrm{MoS}_{2}$ & 1.35 & -2.76 & -32.44 & -1.41 & -4.11 & -35.26 & -31.09 & 0.12 & 0.25 & 0.21 \\
\hline $\mathrm{Zn}$ & 0.60 & -7 & -3.38 & -6.4 & -7.6 & -16.18 & -2.78 & 0.17 & 0.39 & 0.26 \\
\hline $\mathrm{C}_{7} \mathrm{H}_{12}$ & -1030 & -240 & 379 & -1270 & 790 & -2161 & -651 & 0.39 & 0.47 & 0.44 \\
\hline $\mathrm{Be}$ & -0.28 & -0.05 & 0.06 & -0.33 & 0.23 & -0.6 & -0.22 & 0.02 & 0.05 & 0.03 \\
\hline $\begin{array}{c}\mathrm{BeCu} \\
(2.4 \mathrm{at} \% \mathrm{Cu})\end{array}$ & -0.35 & -0.03 & 0.43 & -0.38 & 0.32 & -0.33 & 0.08 & 0.006 & 0.06 & 0.03 \\
\hline $\mathrm{TiB}$ & -0.99 & -1.15 & 0.22 & -2.14 & -0.16 & -4.06 & -0.77 & 0.24 & 0.41 & 0.32 \\
\hline
\end{tabular}


$-2 \frac{\bar{v}}{E}=\left(s_{13}+s_{12}\right) \cos ^{2} \theta+\left(s_{13}-s_{12}\right) \cos ^{2} 2 \theta+Q \cos ^{2} \theta \sin ^{2} \theta$

and they are satisfied for $\mathrm{MoS}_{2}$ and $\mathrm{Zn}$ (see Table 1), i.e. these crystals are not also the auxetics on average. Straightforward calculations confirm this for all six partial auxetics. As a result all hexagonal crystals from handbook [6] are nonauxetics on average. Minimum and maximum values of Poisson's ratio $\bar{v}$ averaged over the transverse directions are included in Table 1 . The values of full average Poisson's ratio $\langle v\rangle$ of six crystals which are partial auxetics before averaging are also given in this table.

\section{Anisotropic auxetics}

Equation (1) can be transformed to

$$
-\frac{v}{E}=\frac{1}{2}[(\mathrm{~A}+\mathrm{B})+\mathrm{R} \cos (\psi-\gamma)]
$$

where

$$
\mathrm{R}=\sqrt{(\mathrm{A}-\mathrm{B})^{2}+\mathrm{D}^{2}}, \quad \cos 2 \gamma=\frac{\mathrm{A}-\mathrm{B}}{\mathrm{R}}, \quad \sin 2 \gamma=\frac{\mathrm{D}}{\mathrm{R}} .
$$

According to (1) and (9) the crystals will be complete auxetics if

$$
\mathrm{A}+\mathrm{B}+\mathrm{R}>0
$$

or

$$
4 \mathrm{AB}>\mathrm{D}^{2} \text { at } \mathrm{A}>0, \quad \mathrm{~B}>0 .
$$

For nonauxetics similar conditions have the form

$$
\mathrm{A}+\mathrm{B}+\mathrm{R}<0
$$

or

$$
4 \mathrm{AB}>\mathrm{D}^{2} \text { at } \mathrm{A}<0, \quad \mathrm{~B}<0 .
$$

Such conditions are necessary and sufficient conditions. These results were obtained earlier in [5].

Change of sign of Poisson's ratio for different orientations is characteristic for partial auxetics. Hence, for the boundary of auxeticity $v=0$ for partial auxetics the necessary and sufficient condition has the form

$$
-\mathrm{R} \leq \mathrm{A}+\mathrm{B} \leq \mathrm{R} \text {. }
$$

A similar analysis can be applied to Poisson's ratio averaged over the transverse directions. According to (2), the crystals will complete auxetics on average in transverse directions at

$$
\mathrm{A}+\mathrm{B}>0 \text {. }
$$

The reverse inequality occurs for nonauxetics on average in transverse directions

$$
\mathrm{A}+\mathrm{B}>0 \text {. }
$$

The condition is characteristic for partial auxetics on average in transverse directions

$$
\mathrm{A}+\mathrm{B}=0 \text {. }
$$

These conditions are necessary and sufficient.

In [5] necessary conditions are also presented for the complete auxetics and nonauxetics for various special orientations, when the crystal is stretched in the crystallographic directions [100], [010] и [001] (formula 4.13 and 4.14). For partial auxetics necessary conditions are more complicated at the same special orientations

$$
\begin{aligned}
& -\sqrt{\left(s_{12}-s_{13}\right)^{2}+s_{14}^{2}} \leq s_{12}+s_{13} \leq \sqrt{\left(s_{12}-s_{13}\right)^{2}+s_{14}^{2}} \\
& -\sqrt{\left(s_{12}-s_{23}\right)^{2}+s_{25}^{2}} \leq s_{12}+s_{23} \leq \sqrt{\left(s_{12}-s_{23}\right)^{2}+s_{25}^{2}} \\
& -\sqrt{\left(s_{13}-s_{23}\right)^{2}+s_{36}^{2}} \leq s_{13}+s_{23} \leq \sqrt{\left(s_{13}-s_{23}\right)^{2}+s_{36}^{2}}
\end{aligned}
$$

\section{Special orientations of Poisson's ratio averaged over the transverse directions}

Below an analysis will be carried out for Poisson's ratio $\bar{v}$ the average over the transverse directions for various special orientations.

Two unit vectors $\mathbf{n}$ and $\mathbf{m}$ are necessary to describe Poisson's ratio. The unit vector $\mathbf{n}$ is directed along the axis of tension, and the vector $\mathbf{m}$ is perpendicular to $\mathbf{n}$. Through the Euler angles $\varphi, \theta, \psi$ mutually orthogonal unit vectors $\mathbf{n}$ and $\mathbf{m}$ are represented as follows

$$
\mathbf{n}=\left(\begin{array}{c}
\sin \varphi \sin \theta \\
-\cos \varphi \sin \theta \\
\cos \theta
\end{array}\right)
$$

$$
\mathbf{m}=\left(\begin{array}{c}
-\sin \varphi \cos \theta \cos \psi-\cos \varphi \sin \psi \\
\cos \varphi \cos \theta \cos \psi-\sin \varphi \sin \psi \\
\sin \theta \cos \psi
\end{array}\right) \text {. }
$$

Let us start the analysis for three special cases when the unit vector $\mathbf{n}$ has only one nonzero component:

1) $\mathrm{n}_{1}=1, \mathrm{n}_{2}=\mathrm{n}_{3}=0 . \quad$ This corresponds to $\varphi=\theta=\pi / 2$ and $\mathbf{m}^{\mathrm{T}}=(0, \cos \psi, \sin \psi)$ and then $\mathrm{A}=\mathrm{s}_{12}$, $\mathrm{B}=\mathrm{s}_{13}$. According to (10) the inequality

$$
\mathrm{s}_{12}+\mathrm{s}_{13}>0
$$

is the necessary condition for complete auxetics on average in transverse directions;

2) $\mathrm{n}_{2}=1, \mathrm{n}_{1}=\mathrm{n}_{3}=0$. In this case $\varphi=\pi, \theta=\pi / 2, \mathbf{m}^{\mathrm{T}}=(-$ $\cos \psi, 0, \sin \psi)$ and necessary condition for complete auxetics on average in transverse directions takes the form

$$
\mathrm{s}_{12}+\mathrm{s}_{23}>0
$$

3) $\mathrm{n}_{3}=1, \mathrm{n}_{1}=\mathrm{n}_{2}=0$. This is attained at $\theta=0$ with no restrictions on $\varphi$. Then the necessary condition for complete auxetics on average has the form

$$
\mathrm{s}_{13}+\mathrm{s}_{23}>0 \text {. }
$$

In three other special cases only one of the components of the unit vector $\mathbf{n}$ is equal to zero:

4) $\mathbf{n}^{\mathrm{T}}=(1 / \sqrt{2},-1 / \sqrt{2}, 0)$ and $\mathbf{m}^{\mathrm{T}}=(1 / \sqrt{2} \cos \psi, 1 / \sqrt{2} \cos \psi$, $\sin \psi)$. In this case $\varphi=\pi / 4, \theta=\pi / 2$ and, hence, the necessary condition for the complete auxetics on average in the transverse directions can be written as

$$
\begin{aligned}
& \mathrm{s}_{11}+\mathrm{s}_{22}+2 \mathrm{~s}_{12}+2 \mathrm{~s}_{13}+2 \mathrm{~s}_{23}-\mathrm{s}_{66}-2 \mathrm{~s}_{36}>0 ; \\
& \text { 5) } \mathbf{n}^{\mathrm{T}}=(1 / \sqrt{2}, 0,1 / \sqrt{2}) \text { and } \mathbf{m}^{\mathrm{T}}=(-1 / \sqrt{2} \sin \psi, \cos \psi, 1 / \sqrt{2}
\end{aligned}
$$
$\sin \psi$ ) corresponds $\varphi=\pi / 2, \theta=\pi / 4$. Similarly to the previous case we obtain 


$$
\mathrm{s}_{11}+\mathrm{s}_{33}+2 \mathrm{~s}_{12}+2 \mathrm{~s}_{13}+2 \mathrm{~s}_{23}-\mathrm{s}_{55}+2 \mathrm{~s}_{25}>0
$$

6) $\mathbf{n}^{\mathrm{T}}=(0,-1 / \sqrt{2}, 1 / \sqrt{2})$ and $\mathbf{m}^{\mathrm{T}}=(\cos \psi, 1 / \sqrt{2} \sin \psi, 1 /$ $/ \sqrt{2} \sin \psi)$ corresponds $\varphi=0, \theta=\pi / 4$. Here, the necessary condition for the complete auxetics on average in the transverse directions will have the form

$$
\mathrm{s}_{22}+\mathrm{s}_{33}+2 \mathrm{~s}_{12}+2 \mathrm{~s}_{13}+2 \mathrm{~s}_{23}-\mathrm{s}_{44}-2 \mathrm{~s}_{14}>0 .
$$

In the opposite case for nonauxetics on average in the transverse directions, these conditions will have the opposite sign in the inequalities:

$$
\begin{gathered}
\mathrm{s}_{12}+\mathrm{s}_{13}<0, \mathrm{~s}_{12}+\mathrm{s}_{23}<0, \mathrm{~s}_{13}+\mathrm{s}_{23}<0 \\
\mathrm{~s}_{11}+\mathrm{s}_{22}+2 \mathrm{~s}_{12}+2 \mathrm{~s}_{13}+2 \mathrm{~s}_{23}-\mathrm{s}_{66}-2 \mathrm{~s}_{36}<0, \\
\mathrm{~s}_{11}+\mathrm{s}_{33}+2 \mathrm{~s}_{12}+2 \mathrm{~s}_{13}+2 \mathrm{~s}_{23}-\mathrm{s}_{55}+2 \mathrm{~s}_{25}<0, \\
\mathrm{~s}_{22}+\mathrm{s}_{33}+2 \mathrm{~s}_{12}+2 \mathrm{~s}_{13}+2 \mathrm{~s}_{23}-\mathrm{s}_{44}-2 \mathrm{~s}_{14}<0 .
\end{gathered}
$$

\section{Auxetics at the averaging over all three angles}

Poisson's ratio at the averaging over all three angles is found by integrating (3). By analyzing the experimental data $[6,7]$ we are able to identify 11 auxetics with full averaging, which found the average negative Poisson's ratio $\langle v\rangle$. Namely, these are three tetragonal crystal $\left(\left(\mathrm{K}_{1 / 6} \mathrm{Na}_{1 / 6} \mathrm{Sr}_{1 / 2} \mathrm{Ba}_{1 / 6}\right) \mathrm{Nb}_{2} \mathrm{O}_{6}\right.$, $\mathrm{FeGe}_{2}, \mathrm{RbH}_{2} \mathrm{AsO}_{4}$ ) and eight cubic crystals $\left(\mathrm{Ba}, \mathrm{Sm}_{0.7} \mathrm{Y}_{0.3} \mathrm{~S}\right.$, $\mathrm{Sm}_{0.75} \mathrm{Y}_{0.25} \mathrm{~S}, \mathrm{Sm}_{0.75} \mathrm{La}_{0.25} \mathrm{~S}, \mathrm{Sm}_{0.65} \mathrm{La}_{0.35} \mathrm{~S}, \mathrm{Sm}_{0.75} \mathrm{Tm}_{0.25} \mathrm{~S}, \mathrm{Tm}_{0.99} \mathrm{Se}$, TmSe). In Table 2 for these crystals values of Poisson's ratio at the averaging over all three angles and the maximum and minimum values for Poisson's ratio at the average over the transverse directions are presented. As can be seen from Table 2, there are five crystals that are partial auxetics, but after averaging over all three angles they become auxetics. These crystals are $\left(\mathrm{K}_{1 / 6} \mathrm{Na}_{1 / 6} \mathrm{Sr}_{1 / 2} \mathrm{Ba}_{1 / 6}\right) \mathrm{Nb}_{2} \mathrm{O}_{6}, \quad \mathrm{FeGe}_{2}$, $\mathrm{RbH}_{2} \mathrm{AsO}_{4}, \mathrm{Tm}_{0.99} \mathrm{Se}$ и $\mathrm{TmSe}$.

\section{Summary}

Hexagonal auxetics are analyzed. Necessary and sufficient conditions are obtained for hexagonal auxetics and auxetics on average over the transverse directions. Analysis of hexagonal auxetics shows that the formula for the average over all the transverse directions Poisson's ratio is obtained as a particular condition (at $\psi=\pi / 4$ ) from the formula for Poisson's ratio. For triclinic crystals with an average Poisson's ratio at averaging over the transverse directions the necessary and sufficient conditions are obtained for complete auxetics, partial auxetics and nonauxetics. For some special orienta-

\begin{tabular}{|c|c|c|c|}
\hline Crystal & $\bar{v}_{\max }$ & $\bar{v}_{\min }$ & $<v>$ \\
\hline \multirow[t]{2}{*}{$\left(\mathrm{K}_{1 / 6} \mathrm{Na}_{1 / 6} \mathrm{Sr}_{1 / 2} \mathrm{Ba}_{1 / 6}\right) \mathrm{Nb}_{2} \mathrm{O}_{6}$} & 0.09 & -0.12 & -0.09 \\
\hline & 0.32 & 0.21 & 0.27 \\
\hline $\mathrm{FeGe}_{2}$ & 0.20 & -0.37 & -0.21 \\
\hline $\mathrm{RbH}_{2} \mathrm{AsO}_{4}$ & 0.30 & -0.15 & -0.02 \\
\hline \multirow[t]{2}{*}{$\mathrm{Ba}$} & -0.05 & -0.37 & -0.22 \\
\hline & 0.39 & 0.125 & 0.27 \\
\hline \multirow[t]{2}{*}{$\mathrm{Sm}_{0.7} \mathrm{Y}_{0.3} \mathrm{~S}$} & -0.19 & -0.59 & -0.31 \\
\hline & -0.10 & -0.49 & -0.21 \\
\hline \multirow[t]{3}{*}{$\mathrm{Sm}_{0.75} \mathrm{Y}_{0.25} \mathrm{~S}$} & -0.24 & -0.58 & -0.34 \\
\hline & -0.34 & -0.67 & -0.44 \\
\hline & -0.04 & -0.42 & -0.14 \\
\hline $\mathrm{Sm}_{0.75} \mathrm{La}_{0.25} \mathrm{~S}$ & -0.13 & -0.40 & -0.21 \\
\hline $\mathrm{Sm}_{0.65} \mathrm{La}_{0.35} \mathrm{~S}$ & -0.32 & -0.35 & -0.33 \\
\hline $\mathrm{Sm}_{0.75} \mathrm{Tm}_{0.25} \mathrm{~S}$ & -0.28 & -0.46 & -0.34 \\
\hline $\mathrm{Tm}_{0.99} \mathrm{Se}$ & 0.06 & -0.47 & -0.06 \\
\hline TmSe & 0.02 & -0.54 & -0.11 \\
\hline
\end{tabular}
tions necessary conditions have been written. Also eleven crystals are found, for which Poisson's ratio at averaging the three angles is negative. Eight crystals are cubic crystals, and three - tetragonal.
Auxetics at averaging over all three angles

This work was supported by the Program for Basic Research of the Presidium of the Russian Academy of Sciences №25 and MK-565.2012.1 (L.D.S.).

\section{References}

1. R.V. Goldstein, V.A. Gorodtsov, D.S. Lisovenko. Mechanics of Solids 45(4), 529 (2010). (in Russian) [Гольдштейн Р.В., Городцов В.А., Лисовенко Д.С. Известия РАН, MTT 4, 43 (2010)].

2. R.V. Goldstein, V.A. Gorodtsov, D.S. Lisovenko. Doklady Physics. 56(7), 399 (2011) (in Russian) [Гольдштейн Р.В., Городцов В.А., Лисовенко Д.С. ДАН. 439(2), 184 (2011)].

3. R.V. Goldstein, V.A. Gorodtsov, D.S. Lisovenko. Letters on Materials 2(1), 21 (2012) [Гольдштейн Р.В., Городцов В.А., Лисовенко Д.С. Письма о Материалах 2(1), 21 (2012)].

4. R.V. Goldstein, V.A. Gorodtsov, D.S. Lisovenko. Doklady Physics 57(4), 174 (2012) (in Russian) [Гольдштейн Р.В., Городцов В.А., Лисовенко Д.С. ДАН. 443(6), 677 (2012)] 
5. T.C.T. Ting, D.M. Barnett. J.Appl.Mech. 72(6), 929 (2005).

6. Landolt-Börstein, - Group III Condensed Matter. Berlin: Springer. 1992. V.29a. P.11-188.

7. U. Schärer, A. Jung, P. Wachter. Physica B 244, 148 (1998). 